\title{
Phenomenology in Psychoanalysis: Still an Open Debate?
}

\author{
Alessandra D'Agostino ${ }^{a}$ Milena Mancini $^{b}$ Mario Rossi Monti ${ }^{a}$ \\ ${ }^{a}$ Department of Humanities, University of Urbino, Urbino, Italy; ${ }^{b}$ Department of Psychological, Humanistic, and \\ Territorial Science, University of Chieti-Pescara, Chieti, Italy
}

\section{Keywords}

Phenomenology · Psychoanalysis · Intersubjective matrix ·

Lived experience $\cdot$ Implicit relational knowing

\begin{abstract}
In a recent book Cristopher Bollas, one of the greatest contemporary psychoanalysts, tells about how he began to bring together phenomenology and psychoanalysis in the clinical setting at the beginning of his career. Working with psychotic patients, he realized that it was first necessary to "absorb" their view of reality before being able to reflect on the mad scenarios of psychosis. In what world did they live? How did they perceive it? Only by "mirroring" this back to the patients was it possible to offer them the experience of being in front of someone trying to understand their world view. Today, phenomenology has been spreading over psychoanalysis more than one can think it did in the past. The aim of this paper is to review and discuss the most relevant theoretical-clinical areas characterizing contemporary psychoanalysis in which phenomenology can claim a legitimate (or still illegitimate for someone) position. The main areas that will be discussed are: (a) the larger relational system or field in which human experience is continually shaped, i.e., the intersubjective matrix in which we are embedded; (b) the capacity to think about the "what" of the patients' experi-
\end{abstract}

ence, rather than the "why" (especially with the most severely disturbed ones); and (c) the crisis of the primacy of interpretation in the analytical technique. Obviously, this review does not have the ambition to be exhaustive. Rather, it just wants to (re)open the discussion on a still controversial but very current topic.

(c) 2019 S. Karger AG, Basel

\section{Introduction}

In a recent book Cristopher Bollas [1], one of the greatest contemporary psychoanalysts, tells about the meeting he had at the beginning of his career with a colleague who introduced him to the contributions of phenomenological psychopathology: Lloyd Clarke. Thanks to him, Bollas began to bring together phenomenology and psychoanalysis in the clinical setting. However, he became aware of the usefulness of these teachings only many years later. Working with psychotic patients, he realized that it was first necessary to "absorb" their view of reality before being able to reflect on the mad scenarios of psychosis. In what world did they live? How did they perceive it? Only by "mirroring" this back to the patients was it possible to offer them the experience of being in front of someone trying to understand their world view.

\section{KARGER}

(c) 2019 S. Karger AG, Basel

E-Mail karger@karger.com

www.karger.com/psp
Dr. Alessandra D'Agostino

Department of Humanities, University of Urbino

Via Saffi 15

IT-61029 Urbino (Italy)

E-Mail ales.dagostino@gmail.com 
Bollas' reflection is not isolated. It often happens that only with the progress of clinical experience one can recover the value of patients' lived experiences and how these are organized in the construction of a real lived world. But why - as Bollas asks - did it take a long time? Perhaps because clinical phenomenology was originally dedicated to the understanding and treatment of psychosis, while psychoanalysis had as its main target the treatment of neurotic (hysterical) patients? Or because of a preconceived mistrust towards a phenomenologically oriented approach that does not take into account the role of the unconscious, at least as psychoanalysis understands it? Or, even, because the phenomenological perspective is seen as a perspective that "stops" on the level of lived experience? A level that psychoanalysis looks at with "suspicion," in the belief that the ego is not "master at home." But, perhaps, also because the heuristic-explanatory perspective of psychoanalysis offers a more stimulating view that is more able to meet the expectations of a clinician wanting to find an answer to a question haunting him: why?

Despite all this, phenomenology has been spreading over psychoanalysis today more than one can think it did in the past. The aim of this paper is to review and discuss the most relevant theoretical-clinical areas characterizing contemporary psychoanalysis in which phenomenology can claim a legitimate (or still illegitimate for some) position. According to us, these areas are as follows: (a) the larger relational system or field in which human experience is continually shaped, i.e., the intersubjective matrix in which we are embedded; (b) the capacity to think about the "what" of the patients' experience, rather than the "why" (especially with the most severely disturbed ones); and (c) the crisis of the primacy of interpretation in the analytical technique. In the next paragraphs, we will describe each of these areas in detail together with the authors who made a considerable contribution to their emergence. Obviously, this review does not have the ambition to be exhaustive. Rather, it just wants to (re)open the discussion on a still controversial but very current topic.

\section{From the Intersubjective Matrix}

The first area in which there is evidence of the contribution of phenomenology to contemporary psychoanalytic theory and practice regards the attention to the intersubjective matrix as root of the human experience. Robert Stolorow and colleagues [2-5] have made a great

Phenomenology in Psychoanalysis: Still an Open Debate? contribution in this sense by developing a phenomenology-based theory of intersubjectivity. In more detail, they introduced an approach called "phenomenological contextualism," which tries to overcome the Cartesian isolated-mind thinking dominating psychoanalysis. This approach focuses on the relational contexts in which subjectivity is embedded and addresses the relational contexts from which therapeutic transformations originate. In opposition to the "myth of isolated mind," Stolorow and colleagues [5-7] highlight that all human phenomena are products not of isolated intrapsychic mechanisms, but of mutual interactions between embodied subjects. Individuality thus comes from the "interplay of two subjectivities" [8] and can only be supported by this.

Stolorow and colleagues took inspiration for the development of this approach from Husserl's and MerleauPonty's phenomenology and from Gadamer's hermeneutics. It is beyond the scope of this paper to provide a comprehensive account of the phenomenological understanding of intersubjectivity, but it could be helpful to mention its main assumptions [9-12]. Our relationships are given in a world that is, from the beginning, a shared world of action. Understanding other persons is fully embodied in the sense of being based on the resonance between my body and the other's body, with the other given in his "expressive bodily presence" $[11,13]$. So, intersubjectivity is a sensorimotor, proprioceptive apprehension of others situated in a preverbal communication context based on affective attunement and on an implicit code which is procedural, nonsymbolic, and prereflective [14].

Following this perspective, Stolorow shifts from the motivational primacy of drive to the motivational primacy of affectivity. He describes the intersubjective exchange as the "experience of being understood that supplies its mutative power" [5] and that does not separate "cognition and affect, thinking and feeling, and interpreting and relating" [15]. In other words, intersubjectivity theory goes beyond the Freudian view of human beings: while in classical theory human beings are little more than a bundle of poorly harnessed sexual and aggressive instincts, some of which are directed at objects, in intersubjectivity theory humans are organizers of experience, i.e., subjects. In this latter view, psychoanalysis is seen as the dialogic attempt of two people together to understand one person's organization of emotional experience by making sense together of their intersubjectively configured experience $[16,17]$.

Other phenomena that have traditionally been central in psychoanalytic theorizing - such as conflict, trauma, and fantasy - can similarly be understood as emergent 
properties of intersubjective systems [2]. In this sense, the dynamic unconscious itself is reconceptualized in terms of affect states that have been defensively aborted or walled off because they evoked traumatogenic malattunement from caregivers [3]. Therefore, the very boundary between conscious and unconscious is revealed to be fluid and ever shifting, a product of the changing responsiveness of the surround to different regions of the subject's emotional experience. This idea of a fluid boundary assembling within a dynamic, dyadic, intersubjective system is in contrast with the traditional notion of the repression barrier as a fixed intrapsychic structure [3].

This set of proposals, called "psychoanalytic phenomenology" by Stolorow and colleagues $[4,7,18]$, has relevant clinical implications. The main implication is to consider the interplay between transference and countertransference in psychoanalytic treatment as an intersubjective process reflecting the mutual interaction between patient and analyst. In therapy sessions, the intersubjective field, which is based on the emotional availability of both analyst and patient, becomes a developmental second chance for the patient [16]. Under conditions of severe stress, old intersubjective experiences may return, but now the patient can recognize them and relativize them by reference to their origins in past relational experience.

From the constant interplay between the patient's and analyst's psychological worlds, two basic situations can emerge: intersubjective conjunction and intersubjective disjunction [2]. Conjunction occurs when the principles organizing the patient's experiences give rise to similar configurations in the psychological life of the analyst. Disjunction, by contrast, occurs when the analyst assimilates the patient's material into configurations that are significantly different in meaning when compared to the patient's perspective. When the analyst is able to become reflectively aware of the principles organizing his/her experience of the therapeutic relationship, the correspondence or disparity between the subjective worlds of patient and analyst can be used to promote understanding and insight [6].

\section{Exploring the "What" of the Experience}

A second area in which phenomenology seems to have been absorbed by contemporary psychoanalysis deals with the exploration of the "what" of the patients' experience rather than the "why." In this sense, Anne Alvarez's contribution [19-21] is crucial. In a sort of 25-year psy- choanalytic work report, Alvarez [21] shows how the project to reach extremely disturbed patients with interpretations is doomed to failure. With a series of clinical examples, the author illustrates how traditional interpretive interventions do not reach the patients at all, or even make them worse, even when the borderline or psychotic patients are young. According to Alvarez's experience, this happened both when the interpretations were of the "why-because" type, i.e., centered on an openly explanatory intent, and when they were instead of the "whowhere" type, i.e., focused on recognizing and replacing split or projected parts of the personality in the patient.

The problem is that - Alvarez argues - both types of interpretation try to replace one meaning with the other: what is conscious with what is unconscious. Or what is rejected with what belongs to one. But what do patients with such severe diseases understand about our interpretations? How should we talk to them? Over the years, Alvarez had to realize that the hypothesis that serious patients (in the psychotic or borderline area) would have the ability to understand an explanatory interpretation is in fact unfounded. Most of them are not capable of a "twoway thinking" [22], i.e., they are not able to think two thoughts or contain two emotions at the same time, and therefore they cannot be reached by this type of interpretation. A therapist animated by an excess of zeal or an uncritical faith in the therapeutic power of the psychoanalytic explanation will inevitably collide with burning disappointments when working with patients who do not seem to derive any benefit from his/her important revelations [19].

Having acquired this awareness, Alvarez had to learn to move to another level where it is first necessary to give a name to the experience. This means that there are situations in which it is better to avoid the whole issue of "who" is having the experience or "why" one is having an experience and spend more time exploring the "what" of that experience. For example, if the patient feels very persecuted or desperate, or simply confused, it might be better to try to qualify this state with one or two adjectives, hook one or two adverbs to the verb, and leave it "lying fallow” [23]. By taking inspiration from Khan's metaphor, Alvarez highlights the necessity of a very intimate and conflict-free area of self-experience functioning as a determinant element in the process of individuation.

During psychoanalytic therapy, there are moments in which patients must be helped to find their own capacity to "lie fallow" by developing the capacity to remain quietly alone in the presence of the other, "in a state which is at the same time transitional, not conflictual, not instinc- 
tual, not integrated, receptive, unstable and, to a large extent, not verbal" [24]. According to Alvarez [20], this therapeutic stance can be necessary not just with patients who have the most serious pathologies, but even with those patients who seem to be less seriously disturbed.

In other words, many times naming or describing a firsthand experience must have priority over the need to place the experience both in the sense of answering the question of who is speaking and in the sense of inscribing this experience in a causal path. Often the experiences that the patients are having are so terrifying that they can hardly be named, let alone explained [19]. In these situations, the patients can take only as much as they can bear from these interventions. A comment, an impersonal statement made by the analyst allows at least to take a perspective on what is being experienced. For all these reasons, Alvarez strongly suggests (with a rich clinical documentation) that it is better to avoid early explanatory interpretations with patients in psychotic or borderline conditions. These interventions simply do not reach the patient. So, before exploring the thoughts that lie in the depths of the unconscious, it may be necessary to explore preconscious and paraconscious experiences, i.e., thoughts that are near, perhaps very close, to conscious thoughts [21].

It is indeed a matter of giving priority to the lived experience. And, although Alvarez does not explicitly recognize this debt, this is a specific patrimony of the phenomenological tradition in psychopathology and psychotherapy. Since the time in which Jaspers [25] postulated a link between phenomenology and psychopathology, phenomenological psychopathology has been a "psychology of the pathological" that tries to catch human, psychopathological experiences through the method of "suspension of judgement" or of "putting into brackets" our usual knowledge of the world. This is not just a description of the subjective experiences of patients with mental disorders, but rather "a search for their conditions of possibilities - the structures of subjectivity that underpin the experience of reality, which, when modified, determine psychopathological life-worlds" [26].

\section{"Something More" than Interpretation}

The third and last area in which phenomenology appears to have been incorporated by contemporary psychoanalytic thought and clinic is related to the progressive shift in recent times from the strict field of interpretations to what we could call side factors, implicit ingredients, or preparatory and facilitating factors of interpretative interventions. The authors that in this sense have made the strongest contributions are those of the Boston Change Process Study Group (BCPSG): D.N. Stern, L.W. Sander, J.P. Nahum, A.M. Harrison, K. Lyons-Ruth, A.C. Morgan, N. Bruschweiler-Stern, and E.Z. Tronick. In 1998, they published a paper [27] in which they put down in black and white something that has been circulating in the psychoanalytic movement for some time, i.e., that there is a need for something more than interpretation in order to promote change in psychoanalytic therapies. But what is this "something more"?

Despite the fact that many psychoanalysts, beginning early in the psychoanalytic movement and accelerating up to the present, directly or indirectly addressed this issue [28-35], this "something more" has remained imprecisely related to the whole "hinterland of interpretation" [24] for many years. By applying a developmental perspective to clinical material, the BCPSG [27] went one step further, defining the "something more" as inherent in the interactional intersubjective process and regarding the realm of the implicit relational knowing.

"Implicit relational knowing" is a sort of primary interpersonal meaning system that represents the relational transactions starting at birth and continuing throughout life $[27,36]$. In other words, "it is the intuitive sense, based on one's history, of how to be with another" [37]. It is based on affect and action, not on word and symbol. It is unconscious but not under repression. So, it can be brought to consciousness and verbalized, but usually not without difficulty. Also, as already mentioned before, "implicit relational knowing" is a relevant dimension in the therapeutic situation. It refers to intersubjective moments occurring between patient and analyst that can create new organizations in or reorganize not only the relationship between them, but more importantly the patient's implicit procedural knowledge, his/her ways of being with others $[27,38]$. However, in order to achieve therapeutic change that is not based on interpretation, this concept must be related to another two: (a) real relationship and (b) moment of meeting.

The first one, "real relationship," is the intersubjective field made of the intersection of the patient's and the therapist's implicit relational knowing; it goes beyond the transference-countertransference dimension, including authentic personal engagement and reasonably accurate sensing of each person's current "ways of being with" [36]. The second one, "moment of meeting," is when the intersubjective state of the patient-analyst dyad is altered/ rearranged by a fitting together of the initiatives of the 
interactants; it is the moment in which there is a specific recognition of the other's subjective reality and each partner grasps a similar version of "what is happening now, between us" [36, 38]. These "moments of meeting" between patient and therapist may or may not become the subject of interpretation, but, in any case, they allow the elaboration of a more complex and coherent way of being together, changing how relational possibilities are represented in each participant's "implicit relational knowing" [38].

Leaving out the criticisms that have been made to this conceptualization by a number of analysts [39-41], this concept of "implicit relational knowing" is in line with the concepts proposed by other authors in order to define several relational phenomena. These include especially Bowlby's "internal working models" of attachment [42], Bollas' concept of "unthought known" [43], Stern's "proto-narrative envelopes" and "schemas of being-with" [44], Sander's "themes of organisation" [45], Trevarthen's "relational scripts" [46], and, from a more epistemological point of view, Loch's hermeneutic conception of the countertransference and Argelander's concept of "scenic understanding," as discussed by Bohleber [47]. Besides, "implicit relational knowing" is a construct that, according to the BCPSG's thinking, raises also the concept of "internal object relations" to a more general representational systems conception, because it is a more articulated, integrated, flexible, and complex concept (a) regarding normal and pathological knowings, (b) integrating affect, fantasy, as well as behavioral and cognitive aspects, and (c) constantly being updated and "recognized" as it is accessed in day-to-day interaction.

However, "implicit relational knowing" has considerable assonances even with the concept of empathy developed by Husserl's well-known pupil Edith Stein [48]. Trying to address "the problem of other minds," Stein considered "empathy" as an irreducible intentional state in which both other persons and the mental states of other persons are given to us [49]. Stein [48] called the internal mental states of other persons "foreign experiences." Foreign individuals are given to us as "living bodies" and in each case as an "I." This means that one is given to the other as an object that bears psychological states, i.e., as a person with an inner life or an autonomous source of intentions, thoughts, wishes, and emotions [49]. In this way, Stein highlighted that the phenomenon of other people's psychic life exists and cannot be put into doubt [24], recognizing this is an act that constitutes the full experience of the self and of the world.
Following this perspective, "implicit relational knowing" seems to have something in common with a "phenomenological" conceptualization of the unconscious, i.e., a structure of pre-psychological experience: a sort of preparatory work of representation to make the world intelligible [24]. According to this view, there is some unconscious permeating consciousness itself in the same way as there is silence between words, in events, and in emotions. This unconscious is somehow different from the Freudian one and therefore not in opposition to it.

\section{Conclusion}

As Bollas highlights, the constitution of a new, common area of clinical intervention consisting particularly of the borderline area has forced many psychoanalysts to renounce to interpretations based on the idea of an explanatory "unmasking" (more suited to the traditional treatment of neurotic patients) and become aware of the fundamental role of putting attention on the level of the immediate, subjective experience of the patients in order to reach them where they are. It is of little importance to know whether a sort of magical encounter between phenomenology and psychoanalysis has taken place or whether the same result has been reached by different pathways.

The point is that, in the most recent years, psychoanalysis has decided to tackle work at its frontiers, or border areas, the most problematic of which is certainly the one concerning a shift away from a predominantly objectcentered focus towards researching the subject him- or herself. Therefore, that "phenomenological temptation" in psychoanalysis that André Green [50] looked at with suspicion and saw as a trap seems today to have become one of the ways allowing further "extensions" [51] of psychoanalysis. At the same time, for many phenomenological training clinicians, the encounter with the turbulent borderline relational style is an opportunity to test the extraordinary heritage of knowledge developed around the nature of lived experiences and psychopathological worlds in the clinic and in psychotherapy.

\section{Disclosure Statement}

The authors report no conflict of interest relevant to this work. 


\section{References}

1 Bollas C. When the sun bursts. The enigma of schizophrenia. Yale: Yale University; 2015.

2 Stolorow RD, Atwood GE. Contexts of Being: The Intersubjective Foundations of Psychological Life. Hillsdale (NJ): The Analytic Press; 1992.

3 Stolorow RD. Dynamic, dyadic, intersubjective systems: An evolving paradigm for psychoanalysis. Psychoanal Psychol. 1997;14(3): 337-46.

4 Stolorow RD, Atwood GE, Orange DM Worlds of experience: Interweaving philosophical and clinical dimensions in psychoanalysis. New York (NY): Basic Books; 2002.

5 Stolorow RD. Intersubjective-systems theory: A phenomenological-contextualist psychoanalytic perspective. Psychoanal Dialogues. 2013;23(4):383-9.

6 Stolorow RD, Atwood GE, Branchaft B. The intersubjective perspective. Northvale (NJ): Jason Aronson; 1994.

7 Atwood GE, Stolorow RD. Structures of subjectivity: Explorations in psychoanalytic phenomenology and contextualism. New York: Routledge; 2014.

8 Orange DM, Atwood GE, Stolorow RD. Working intersubjectively - Contextualism in psychoanalytic practice. Hillsdale (NJ): The Analytic Press; 1997

9 Zahavi D. Beyond empathy. Phenomenological approaches to intersubjectivity. J Conscious Stud. 2001;8(5-6):151-67.

10 Sass L, Pienkos E. Faces of intersubjectivity. J Phenomenological Psychol. 2015;46(1):1-32.

11 Stanghellini G, Ballerini M, Mancini M. Other persons: On the phenomenology of interpersonal experience in schizophrenia (ancillary article to EAWE domain 3). Psychopathology. 2017;50(1):75-82

12 Stanghellini G, Mancini M. The therapeutic interview in mental health: A values-based and person-centered approach. Cambridge: Cambridge University Press; 2017.

13 Gallagher S. Intersubjectivity and psychopathology. In: Fulford KW, Davies M, Gipps RG, Graham G, Sadler JZ, Stanghellini G, et al., editors. The Oxford Handbook of Philosophy and Psychiatry. Oxford: Oxford University Press; 2013. p. 258-74.

14 Merleau-Ponty M. Phénoménologie de la perception. Paris: Éditions Gallimard; 1945.

15 Stolorow RD. World, affectivity, trauma: Heidegger and post-Cartesian psychoanalysis. New York (NY): Routledge; 2011.

16 Orange DM. Emotional understanding. London/New York: Guilford; 1995.

17 Hartmann HP. Psychoanalytic self psychology and its conceptual development in light of developmental psychology, attachment theory, and neuroscience. Ann N Y Acad Sci. 2009 Apr;1159(1):86-105.
18 Stolorow RD, Atwood GE. The Power of Phe nomenology: Psychoanalytic and Philosophical Perspectives. New York: Routledge; 2018.

19 Alvarez A. Live company. London: Taylor \& Francis; 1992.

20 Alvarez A: Livelli di lavoro analitico e livelli di patologia. Paper read at the Centro Psicoanalitico di Firenze, April 20, 2002.

21 Alvarez A. The thinking heart: Three levels of psychoanalytic therapy with disturbed children. Hove: Routledge; 2012.

22 Bruner J. Processes of cognitive growth: Infancy. Worcester: Clark University Press; 1968.

23 Khan M. On lying fallow. In: Hidden selves: between theory and practice in psychoanalysis. London: Hogarth Press; 1977. p. 183-8.

24 Rossi Monti M. New interpretative styles: Progress or contamination? Psychoanalysis and phenomenological psychopathology. Int J Psychoanal. 2005 Aug;86(Pt 4):1011-32.

25 Jaspers K. General psychopathology. Baltimore (MD): Johns Hopkins Univ. Press; 1913.

26 Messas G, Tamelini M, Mancini M, Stanghellini G. New perspectives in phenomenological psychopathology: Its use in psychiatric treatment. Front Psychiatry. 2018 Sep;9:466.

27 Stern DN, Sander LW, Nahum JP, Harrison AM, Lyons-Ruth K, Morgan AC, et al. Noninterpretive mechanisms in psychoanalytic therapy. The "something more" than interpretation. The Process of Change Study Group. Int J Psychoanal. 1998 Oct;79(Pt 5): 903-21.

28 Ferenczi S, Rank O. The Development of Psychoanalysis. Madison (CT): Int. Univ. Press; 1924.

29 Strachey J. The nature of the therapeutic action of psychoanalysis. In: Bergmann M, Hartman F, editors. The evolution of psychoanalytic technique. New York: Basic Books; 1934. p. 331-60.

30 Greenson RR. The technique and practice of psychoanalysis. Volume I. New York: Int. Univ. Press; 1967.

31 Loewald HW. The transference neurosis: Comments on the concept and the phenomenon. J Am Psychoanal Assoc. 1971 Jan;19(1): 54-66.

32 Winnicott DW. The child and the family. London: Tavistock; 1957.

33 Sandler J. Projection, identification, projective identification. New York: Int. Univ. Press; 1987.

34 Mitchell S. Hope and dread in psychoanalysis. New York: Basic Books; 1993.

35 Greenberg J. Psychoanalytic words and psychoanalytic acts. Contemp Psychoanal. 1996; 32(2):195-213.

36 Lyons-Ruth K, Bruschweiler-Stern N, Harrison AM, Morgan AC, Nahum JP, Sander L, et al. Implicit relational knowing: Its role in development and psychoanalytic treatment. Infant Ment Health J. 1998;19(3):282-9.
37 Bruschweiler-Stern N, Lyons-Ruth K, Morgan AC, Nahum JP, Sander LW, Stern DN; BCPSG. The foundational level of psychodynamic meaning: Implicit process in relation to conflict, defense and the dynamic unconscious. Int J Psychoanal. 2007 Aug;88(Pt 4): 843-60.

38 Bruschweiler-Stern N, Harrison AM, LyonsRuth K, Morgan AC, Nahum JP, Sander LW, et al.; Boston Change Process Study Group. Explicating the implicit: The local level and the microprocess of change in the analytic situation. Int J Psychoanal. 2002 Oct;83(Pt 5): 1051-62.

39 House J, Portuges S. Relational knowing, memory, symbolization, and language: Commentary on the Boston Change Process Study Group. J Am Psychoanal Assoc. 2005;53(3): 731-44.

40 Litowitz BE. When "something more" is less: Commentary on the Boston Change Process Study Group. J Am Psychoanal Assoc. 2005; 53(3):751-9.

41 Modell AH. Implicit or unconscious? Commentary on paper by the Boston Change Process Study Group. Psychoanal Dialogues. 2008;18(2):162-7.

42 Bowlby J. Separation. Attachment and loss. Volume II. New York: Basic Books; 1973.

43 Bollas C. The Shadow of the Object: Psychoanalysis of the Unthought Known. London, UK: Free Association Book; 1987.

44 Stern DN. The motherhood constellation. New York: Basic Books; 1995.

45 Sander L. Paradox and resolution. In: Osofsky J, editor. Handbook of Child and Adolescent Psychiatry. New York: John Wiley; 1997. p. 153-60.

46 Trevarthen C. Brain, science and the human spirit. In: Ashbrook JB, editor. Brain, Culture and the Human Spirit. Lanham: Univ. Press America; 1993. p. 129-81.

47 Bohleber W. Between hermeneutics and natural science: Some focal points in the development of psychoanalytic clinical theory in Germany after 1945. In: Leuzinger-Bohleber M, Dreher AU, Canestri J, editors. Pluralism and Unity? Methods of Research in Psychoanalysis. London: International Psychoanalytical Association; 2003. p. 63-80.

48 Stein E. On the problem of empathy. Washington, DC: ICS Publication; 1989.

$49 \mathrm{McDaniel}$ K. Edith Stein: On the problem of empathy. In: Schliesser E, editor. Ten neglected classics of philosophy. Oxford: Oxford University Press; 2016. p. 195-222.

50 Green A. On private madness. London: Hogarth Press; 1986.

51 Kaës R. L'extension de la psychanalyse. Pour une métapsychologie de troisième type. Paris: Dunod; 2015 